\title{
Studies on the supramolecular interactions in functionalized imidazolium-based ionic liquids
}

\author{
Alberto A. R. Mota*, Cláudia J. do Nascimento, Claudia C. Gatto, Brenno A. D. Neto \\ Laboratory of Medicinal and Tecnological Chemistry, Chemistry Institute, University of Brasilia (IQ-UnB) \\ *albertomotabr@gmail.com
}

Keywords: ionic liquids, supramolecular aggregates, NMR

\section{INTRODUCTION}

In the last ten years, ionic liquids (ILs) have emerged as very attractive media for many areas of chemistry. The properties of these substances are very attractive, especially considering environmental issues. ${ }^{1}$

The use of NMR is a powerful tool to study ILs supramolecular interactions and has been utilized since the rise of these substances. ${ }^{2}$

Herein, we present studies on the relaxation times (T1), for observing of supramolecular aggregates, conductivities and X-ray crystallographic analysis.

\section{RESULTS AND DISCUSSION}

All T1 measurements were realized in aqueous solutions. An external standard $\left(C_{6} D_{6}\right)$ was used (7.16ppm). Studies were realized in a Varian spectrometer (7.05 T) using the inversion recovery of T1. The electrical conductivities was realized also in aqueous solution, in a mixture of water: Acetonitrile $\left(\mathrm{H}_{2} \mathrm{O}-\mathrm{Ac} . \mathrm{N}\right)$ at various concentrations. Initially, we used the functionalized IL 1-methyl-3carboxymethylimidazolium chloride (Figure 1).<smiles></smiles>

Figure 1. Structure of the functionalized IL 1-methyl-3carboxymethylimidazolium chloride with enumerated hydrogens.

The crystal structures showed the existence of interaction between the chloride anion and the imidazolium cation via $\mathrm{C}-\mathrm{H} \cdots \mathrm{Cl}$ hydrogen bonding as well as an interaction between $\mathrm{C} \cdots \mathrm{Cl}$ (Figure 2).

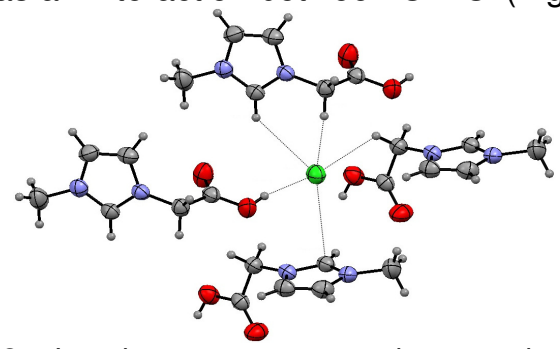

Figure 2. Local structure around an anion of the functionalized IL. The dotted lines show the anion interactions.

$14^{\text {th }}$ Brazilian Meeting on Organic Synthesis $-14^{\text {th }}$ BMOS - September 01-05, 2011-Brasilia, Brazil
T1 measurements can be seen in Figure 3 and electrical conductivities in Figure 4.

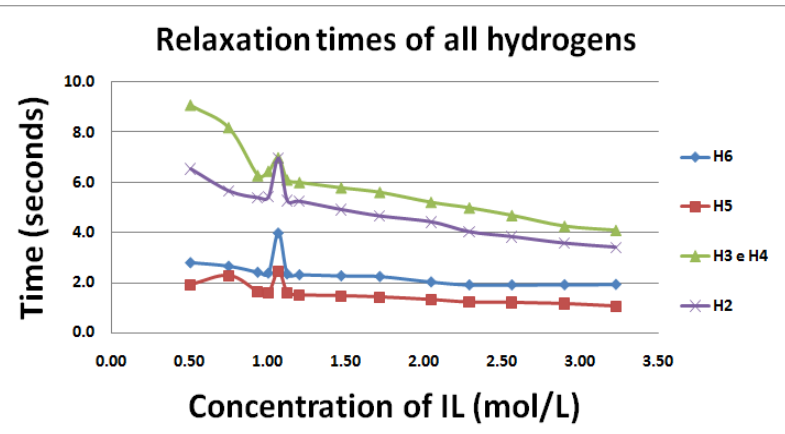

Figure 3. Relaxation times T1 in different concentrations.

At about $1 \mathrm{~mol} / \mathrm{L}$, the transition to form the supramolecular aggregates in water is observed. This is suported by the increase in the relaxation times.

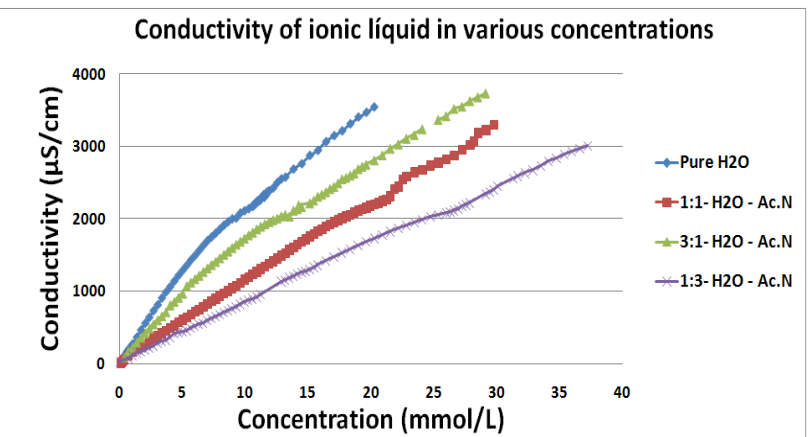

Figure 4. Conductivity of the IL in different concentrations.

\section{CONCLUSION}

Through the different analysis we observed interesting interactions cation-anion forming supramolecular aggregates with "magic numbers" are preferred to free ions and ionic pairs.

\section{ACKNOWLEDGEMENTS}

CNPq, FAPDF and CAPES for financial support.

\section{REFERENCES}

${ }^{1}$ Silva, W. S. D., Lapis, A. A. M., Suarez, P. A. Z., Neto, B. A. D.

J. Mol. Cat. B: Enzymatic 2011, 68, 98.

${ }^{2}$ Ananikov, V. P. Chem. Rev. 2011, 111, 418.

${ }^{3}$ Gozzo, F. C.; Santos, L. S.; Augusti, R.; Consorti, C. S.; Dupont,

J.; Eberlin, M. N. Chem.-Eur. J. 2004, 10, 6187. 